\title{
A condição de distintividade na variação do sujeito pronominal de primeira pessoa do singular em cartas escritas por um capixaba
}

\author{
The distinctiveness condition in the variation of the first person \\ singular pronoun subject in personal letters of a Espírito Santo writer
}

\author{
Caroliny Batista Massariol ${ }^{1}$ \\ Lilian Coutinho Yacovenco ${ }^{2}$
}

Resumo: No presente estudo, por meio de uma análise sociofuncionalista (NEVES, 1999; GÖRSKI; TAVARES, 2013), observamos o efeito da ambiguidade sobre a variação do sujeito pronominal em 33 cartas pessoais escritas por um capixaba. Utilizamos como base deste estudo os apontamentos de Kiparsky (1972 apud POPLACK, 1980) acerca da condição de distintividade; os estudos de Paredes Silva (1988) e de Duarte (1993), sobre a variação da expressão do sujeito pronominal; os pressupostos teóricos da Sociolinguística Variacionista, de Labov (2008 [1972]); a Sociolinguística histórica de Hernàndez-Campoy; Schilling (2012) e de Conde Silvestre (2007); o detalhamento de Guy e Zilles (2007) sobre o pacote de programas Varbrul. Verificamos nas cartas manuscritas que contextos de ambiguidade morfológica e contextual favorecem o uso do sujeito pronominal explícito, ratificando, assim, a condição de distintividade proposta por Kiparsky (1972 apud POPLACK, 1980).

Palavras-chave: Sujeito pronominal. Primeira pessoa do singular. Cartas pessoais. Sociofuncionalismo.

Abstract: Under socio-functionalist approach (NEVES, 1999; GÖRSKI; TAVARES, 2013), we analyze the effect of ambiguity on the variation of the pronominal subject in 33 personal letters written by a man born in the state of Espírito Santo - Brazil. We based our study on Kiparsky's (1972 apud POPLACK, 1980) researche about the distinction condition; on Paredes Silva's (1988 and Duarte's studies (1993) about the variation of the pronominal subject; on Labov's studies (2008 [1972], 2001) about linguistic variation and change; on HernàndezCampoy's; Schilling's (2012) and on Conde Silvestre's (2007) about the Historical sociolinguistics; and on Guy \& Zilles (2007) considerations about Varbrul, the statistic program used in our research. We verified that contexts of morphological and contextual ambiguity favor the use of the explicit pronominal subject. These results confirm the proposal of the condition distinctiveness, proposed by Kiparsky (1972 apud POPLACK, 1980).

Keywords: Pronominal subject variation. First-person singular. Personal letters. Sociofuncionalism.

\footnotetext{
${ }^{1}$ Universidade Federal do Rio de Janeiro, Programa de Pós-Graduação em Linguística, Rio de Janeiro, RJ, Brasil. Endereço eletrônico: carolinymassariol@gmail.com.

${ }^{2}$ Universidade Federal do Espírito Santo, Departamento de Línguas e Letras, Programa de Pós-Graduação em Linguística, Vitória, ES, Brasil. Endereço eletrônico: lilianyacovenco@yahoo.com.br.
} 


\section{Considerações iniciais}

Este artigo tem como foco central o estudo da variação do sujeito pronominal em 33 missivas pessoais novecentistas ${ }^{3}$, manuscritas por Oswald Guimarães para Hylda Mattos Guimarães. A partir do controle da ambiguidade contextual, com base em Paredes Silva (1988), e da hipótese da distintividade, de Kiparsky (1972 apud POPLACK, 1980), pretendemos discutir se tal fator condiciona o maior preenchimento do sujeito pronominal de primeira pessoa do singular.

Diversos estudos sobre o sujeito pronominal foram desenvolvidos, seja com dados da fala ou da escrita. Destacamos, entre eles, os de Paredes Silva (1988, 1998), sob o prisma sociofuncionalista, e o de Duarte (1993), de escopo socioparamétrico. Os três estudos apontam o uso frequente de sujeitos pronominais plenos, sendo uma das razões, segundo Duarte (1993), o enfraquecimento do paradigma flexional do português brasileiro. A autora propõe a existência de três paradigmas: um com riqueza flexional, com seis formas morfológicas designando seis pessoas do discurso; um segundo com menos riqueza flexional, em que há apenas quatro formas morfológicas, uma vez que a segunda pessoa passa a ter sua expressão com verbos de terceira pessoa (segunda pessoa indireta, no dizer da autora); e, por último, um paradigma com maior enfraquecimento flexional, de somente três formas morfológicas, em que, além da segunda pessoa, a primeira do plural também é expressa por formas verbais de terceira pessoa do singular (a gente).

Sob um enfoque sociofuncionalista, Paredes Silva (1998) aponta que a ambiguidade contextual, um fator funcional, atua fortemente sobre a expressão de sujeitos pronominais, já que acarreta a necessidade de sujeitos pronominais plenos para que a comunicação se torne clara nos casos de ambiguidade contextual. A autora também discute a condição de distintividade, proposta por Kiparsky (1972 apud POPLACK, 1980), segundo a qual "há uma tendência para a informação semanticamente relevante ser mantida na estrutura superficial" (PAREDES SILVA, 1998, p. 132). Portanto, tanto a ambiguidade contextual, quanto a condição da distintividade reforçam a necessidade, no caso dos sujeitos pronominais, de sua expressão plena para que se desfaçam possíveis vazios semânticos e/ou equívocos na comunicação.

No presente artigo, procuramos observar como era a língua dos capixabas no início dos anos 1900 e, para isto, optamos por fazer uma reconstrução histórica por meio da escrita de cartas pessoais daquele período.

\footnotetext{
${ }^{3}$ A presente análise é um recorte da dissertação de Massariol (2018a), na qual foram analisadas outras variáveis linguísticas e extralinguísticas, além da que consta na presente análise. Também foram analisados cartões postais escritos por outro capixaba.
} 
Analisamos, no caso em tela, a alternância que um missivista faz entre a forma plena ou não do sujeito pronominal de primeira pessoa do singular, observando, mais especificamente, como a variável ambiguidade atua sobre a escolha dessas variantes.

Sobre o sujeito pronominal, a tradição gramatical preconiza que não deve ser expresso, sendo, portanto, o preenchimento recomendado apenas para: (1) dar ênfase à pessoa do discurso, (2) evitar ambiguidades e (3) opor as pessoas gramaticais (ROCHA LIMA, 2011; CUNHA; CINTRA, 2001). Tal postulação é ratificada pela condição de distintividade, que se baseia, conforme dito, na manutenção na estrutura superficial de informação semanticamente relevante (KIPARSKY, 1972, apud POPLACK, 1980, p. 372). Notamos, assim, desde os estudos de Paredes Silva (1988, 1998), que a ocorrência de sujeitos pronominais expressos se dá para que a informação semântica seja garantida. Logo, o uso de uma estrutura linguística (o sujeito pronominal), indispensável para a comunicação ocorrer de maneira eficaz, nos casos de ambiguidade contextual, tende a não ser apagada, conforme expresso pela condição de distintividade. Portanto, a expressão do sujeito pronominal se dá para garantir o entendimento do sujeito da sentença. Ao utilizar o sujeito pronominal, o missivista busca não deixar dúvida ao leitor, evitando, então, mensagens ambíguas. Sendo assim, conforme já descrito pela tradição gramatical, o uso de sujeitos pronominais evita ambiguidades e opõe pessoas, daí podermos considerar verdadeira a existência de relação entre distintividade e ambiguidade.

A hipótese funcionalista por detrás da variável analisada faz com que o presente estudo se enquadre no campo denominado sociofuncionalista, uma vez que alinha duas teorias, a Sociolinguística Variacionista e o Funcionalismo. Esse tipo de estudo, no Brasil, tem sido frequente, tendo se destacado, inicialmente, na década de 1980 no Projeto Peul (Programa de Estudos sobre o Uso da Língua) / UFRJ (Universidade Federal do Rio de Janeiro) (NEVES, 1999; GÖRSKI; TAVARES, 2013). Sobre o estudo do fenômeno em questão, destacamos a tese desenvolvida por Paredes Silva (1988).

Este artigo está estruturado da seguinte maneira: (i) pressupostos teóricos da Sociolinguística e o corpus de pesquisa; (ii) o Sociofuncionalismo; (iii) a expressão do sujeito pronominal em cartas capixabas; (iv) as cartas pessoais: uma reconstrução histórica da variação linguística capixaba nos novecentos; (v) a hipótese funcionalista da variável ambiguidade: aliança entre gregos e troianos; (vi) descrição dos resultados e (vii) considerações finais.

\section{Pressupostos teóricos da Sociolinguística e o corpus de pesquisa}

O campo teórico da Sociolinguística surge por meio de reflexões críticas aos postulados das escolas estruturalista e gerativista. A partir disso, questiona-se a organização da língua e a 
sua relação com o meio social. Um dos pontos mais relevantes para a Sociolinguística é a constatação de que não há variação livre, uma vez que a variação, para esta teoria, é sistematizada, sendo ordenada a partir de condicionamentos sociais, estilísticos, cognitivos e linguísticos que favorecem o uso de uma forma linguística em detrimento de outra. (WEINREICH; LABOV; HERZOG, 2006, p. 35; FISCHER, 1974, p. 88). Dessa forma, W. Labov ([1972] 2008) postula que as línguas se caracterizam por serem inerentemente variáveis, ou seja, nas línguas há estruturas linguísticas que possuem duas ou mais formas variantes, as quais têm a possibilidade de dizer a mesma coisa com o mesmo valor de verdade.

Outra importante contribuição diz respeito ao modo de se conceber a mudança linguística, que, para a Sociolinguística, ocorre forma lenta e gradual: em um primeiro momento, há a variação entre duas ou mais formas, que disputam espaço no sistema linguístico para, posteriormente, em alguns casos, uma dessas variantes, a mais nova, superar a mais antiga. Podemos notar que, de acordo com os pressupostos teóricos da Sociolinguística, toda e qualquer mudança pressupõe variação; porém, nem toda variação ocasiona mudança linguística. (WEINREICH; LABOV; HERZOG, 2006, p. 125-126).

Inicialmente, esse campo teórico centrou-se em estudos voltados para a língua falada, destacando-se os estudos de J. Fischer ([1958] 1974) sobre a variação entre -ing e -in na fala de crianças da Nova Inglaterra; os de W. Labov ([1972] 2008) acerca da variação sonora dos ditongos /ay/ e /aw/ na ilha de Martha's Vineyard, localizada no estado de Massachusetts/EUA, e também da variação do /r/ na cidade de Nova Iorque.

Para W. Labov, os estudos sobre variação e mudança linguística deveriam ser baseados no vernáculo, que se caracteriza por ser a língua usada em situações em que as pessoas dão pouca atenção à própria fala, situações de conversas naturais e espontâneas. Entretanto, no caso de observação de mudanças linguísticas, por vezes é necessário que se utilizem dados de escrita, os únicos registrados em determinado tempo. Com respeito a estes dados, Labov afirma que o pesquisador deve praticar a arte de "fazer o melhor uso de dados ruins" (LABOV, 1994, p. 11, tradução nossa ${ }^{4}$ ). Pretendemos, no presente trabalho, usar esta prática, uma vez que, nas primeiras décadas de 1900, não havia gravações de áudio para que fosse possível um estudo do vernáculo capixaba daquela época.

Em busca de se observar mais profundamente o trajeto da mudança linguística, que não fosse pelo construto do tempo aparente, começou-se a questionar como era a língua em

\footnotetext{
4 "Historical linguistics can then be thought of as the art of making the best use of bad data" (LABOV, 1994, p.
} $11)$. 
sincronias passadas. Uma das possibilidades de se fazer isso era por meio da reconstrução da língua em sincronias passadas a partir de materiais escritos, objeto de estudo do presente texto.

A respeito da busca por essa reconstrução histórica da língua, Hernàndez-Campoy e Schilling (2012, p. 63, tradução nossa ${ }^{5}$ ) ressaltam:

O estudo sociolinguístico de formas linguísticas históricas conta com registros linguísticos de períodos anteriores - a maioria dos quais estará incompleta ou não será representativa de algum modo - bem como sobre o conhecimento e o entendimento das situações do passado sociocultural que somente podem ser reconstruídas em vez de diretamente observadas ou experimentadas pelo pesquisador.

O material de análise de cunho histórico pode, entretanto, trazer uma série de problemas de ordem teórico-metodológica para os pesquisadores da área. Conde Silvestre (2007) menciona que as informações que adquirimos, a partir dos textos escritos, são "fragmentárias, escassas e dificilmente vinculáveis com a produção real de seus falantes” (p. 35).

Hernàndez-Campoy e Schilling (2012) elencam sete problemas principais inerentes à pesquisa em sociolinguística histórica, que são: “i) representatividade, ii) validade empírica, iii) invariação, iv) autenticidade, v) autoria, vi) validade histórica e social, vii) ideologia padrão" (p. 63, tradução nossa ${ }^{6}$ ).

Entre os problemas mencionados, destacamos a questão da representatividade (HERNÀNDEZ-CAMPOY; SCHILLING, 2012), que diz respeito à irregularidade dos dados, devida a questões históricas: alguns textos são preservados, por acaso do destino, ou por conta da família ou órgão público os terem guardado e conservado. Por outro lado, há a perda aleatória de outros. Em decorrência disso, os pesquisadores devem ser cautelosos, uma vez que é necessário avaliar quem são os escreventes com os quais eles estão lidando, a que segmentos da população pertencem e que formas de linguagem suas amostras englobam. Em outras palavras, a partir do corpus que possuímos, não podemos fazer generalizações sobre toda a sociedade capixaba da época, uma vez que temos dados referentes, apenas, à escrita de uma pessoa.

\footnotetext{
5 "Historical sociolinguistics has often been considered to suffer, perhaps inevitably, from lack of representativeness and validity of its findings. This is because the sociolinguistic study of historical language forms must rely on linguistic records from previous periods - most of which will be incomplete or non - representative in some way - as well as on knowledge and understanding of past sociocultural situations that can only be reconstructed rather than directly observed or experienced by the researcher" (HERNÀNDEZ-CAMPOY; SCHILLING, 2012, p. 63).

6 “i) representativeness, ii) empirical validity, iii) invariation, iv) authenticity, v) authorship, vi) social and historical validity, and vii) standard ideology” (HERNÀNDEZ-CAMPOY; SCHILLING, 2012, p. 63).
} 
Outro problema relevante é o da invariação, que diz respeito à natureza dos dados, que são de escrita, os quais tendem a ser mais formais, conservadores e normativos, se comparados aos de fala. Por isso, há, mais uma vez, uma restrição, dessa vez quanto à probabilidade de variação. O pesquisador, ao lidar com esse problema, deve ter cuidado ao ver aparente uniformidade ou, por outro lado, variabilidade. Esta pode ser devida a diferenças dialetais, demográficas /sociológicas ou, ainda, as diferenças estilísticas entre os escreventes ou entre os períodos de tempo (HERNÀNDEZ-CAMPOY; SCHILLING, 2012).

O problema da autoria ocorre, principalmente, em correspondências privadas (corpus de nosso estudo). As cartas podem ser escritas por outras pessoas que não o remetente, uma vez que, em sincronias passadas, o analfabetismo atingia grande parte da sociedade brasileira. Não há esse problema nas cartas ora analisadas, uma vez que quem as concedeu foi a neta do casal, que nos contou a história das missivas trocadas por seus avós. As cartas foram escritas por seu avô e não por um copista. Cabe também ressaltar que o escrevente pertencia à elite capixaba. Era empresário de destaque, participando ativamente da vida pública capixaba, tendo sido, inclusive, prefeito de Vitória, capital do estado, por um curto período de tempo. Em suas cartas, constatamos que frequentava lugares de prestígio, como teatros e clubes sociais, participava de eventos prestigiados, como concertos musicais, encenação de peças teatrais, conferências e reuniões políticas.

\section{O Sociofuncionalismo}

Utilizamos como base deste artigo o alinhamento teórico da Sociolinguística Variacionista (WEINREICH; LABOV; HERZOG, 2006) e do Funcionalismo Linguístico (GIVÓN, 1995). Este alinhamento teórico é conhecido por Sociofuncionalismo e foi abordado com notoriedade em estudos do Peul/UFRJ a partir da década de 1980 (NEVES 1999; GÖRSKI e TAVARES, 2013) e expandido no cenário nacional. No Espírito Santo, destacamos a pesquisa de Tesch (2011) acerca da expressão do tempo futuro na escrita jornalística capixaba e a desenvolvida por Pinheiro (2020) sobre a variação do verbo estar.

No presente estudo, pretendemos testar a hipótese funcionalista da Condição de Distintividade, que é caracterizada por demonstrar uma tendência das línguas em reterem uma dada informação relevante na estrutura superficial, ou seja, conforme fica nítida a redundância, através de constituinte marcado, isso encadearia uma tendência para que não haja outras marcas, quando não há ambiguidade contextual (KIPARSKY, 1972 apud POPLACK, 1980).

Paredes Silva (1998), conforme exposto inicialmente no presente trabalho, analisa a atuação da Condição de Distintividade sobre sujeitos pronominais de segunda pessoa em dados 
de fala, extraídos das gravações que compõem o Banco de Dados Interacionais (BID) do Peul/UFRJ. A autora verifica que há predomínio de sujeitos plenos no caso de formas verbais ambíguas, porém não apenas as formas verbais são analisadas, mas, também, o contexto discursivo em que ocorre o pronome. Paredes Silva ratifica, em seu estudo, os resultados de sua pesquisa anterior sobre o sujeito pronominal em cartas pessoais (PAREDES SILVA, 1988) e também, os de Hochberg (1986 apud PAREDES SILVA, 1998) sobre o apagamento do -s de segunda pessoa e o uso de sujeitos pronominais plenos no espanhol de Porto Rico. Nesses estudos, observou-se que há um aumento do uso de sujeitos pronominais explícitos em formas verbais morfológica e contextualmente ambíguos. Paredes Silva (1998) afirma não ser apenas esse o fator que atua sobre o uso de sujeitos pronominais explícitos, mas que é uma variável muito importante neste uso.

Vale ressaltar que enlaces teóricos sempre são muitos discutidos em âmbito acadêmico, como visto com a perspectiva que alinha a Sociolinguística ao Funcionalismo (Sociofuncionalismo), ou a entre a Sociolinguística e a Teoria de Princípios e Parâmetros (Sociolinguística Paramétrica). Entretanto, por vezes observamos que o cunho Sociolinguístico é usado, apenas, como procedimento metodológico para o tratamento quantitativo de dados. Ressaltamos que a análise sociofuncionalista ora utilizada no presente trabalho tem como finalidade observar a variação linguística do sujeito pronominal e os condicionamentos funcionais para o uso de uma variante em detrimento de outra.

\section{A expressão do sujeito pronominal}

Com o intuito de observarmos o português capixaba dos anos 1900, analisamos cartas escritas por um homem capixaba nas duas primeiras décadas dos novecentos. Paredes Silva (1988) e Duarte (1993) já demonstraram que cartas pessoais e peças teatrais, respectivamente, são duas boas fontes para os estudos de sincronias passadas. As cartas pessoais apresentam o caráter da pessoalidade e da proximidade entre o escrevente e o destinatário; e as peças teatrais, por sua vez, procuram reproduzir na fala dos personagens suas características sociais. Sendo assim, ambos os gêneros permitem que se levantem hipóteses sobre o uso da língua em épocas passadas.

O fenômeno variável ora analisado, o sujeito pronominal, não possui estigma social, nem é objeto de atenção por parte de falantes ou interlocutores. Cartas pessoais, sujeitas a uma atuação mais forte dos ensinamentos escolares e cujo monitoramento no uso da língua é maior do que em uma conversa espontânea, parecem ser um gênero que favoreça o uso nulo de sujeitos pronominais que os encontrados na fala, uma vez que, na escrita, há maior pressão para o uso 
de acordo com a tradição gramatical, que não prescreve o uso de sujeitos explícitos, considerados exceções e cujo uso é descrito para situações específicas, conforme as mencionadas anteriormente. Essa distinção de uso na fala e na escrita foi estudada por Duarte (1993) ao comparar o uso de sujeitos pronominais em textos de peças de teatro escritos e encenados, tendo verificado um número maior de sujeitos plenos nos textos encenados. Como não é possível que se observe o vernáculo dos capixabas na época estudada, optamos por analisar as cartas pessoais e, como afirmado por W. Labov, procuramos fazer um bom uso de dados não tão bons (LABOV, 1994, p. 11).

Apesar desse maior monitoramento que há em textos escritos, mesmo em textos considerados mais informais, mais próximos à fala, como é o caso da carta pessoal (MARCUSCHI, 2010, p. 41), notamos uma variação linguística latente, como já demonstrou Paredes Silva (1988) ao analisar cartas de cariocas na década de 1980. Além disso, é importante salientar que estudos linguísticos de natureza histórica apontam que as variantes inovadoras são vistas, inicialmente, em produções escritas de natureza mais informal, como as cartas, e, também, sendo estas destinadas a pessoas mais íntimas.

O sujeito pronominal pode ser expresso de duas maneiras: (a) presente/explícito/pleno"Eu acho que não passa do que está" (exemplo retirado da carta datada de 5 de Maio, de 1917); (b) nulo/ausente- "Ø acho que deves fazer um esforço para regressar" (exemplo retirado da carta datada 20 de Março de 1926).

Diversos estudos sobre o tema, entre os quais os de Paredes Silva (1988) e Duarte (1993), apontam uma mudança no sistema pronominal, que acaba por desencadear uso mais frequente de sujeitos explícitos. A inserção de formas nominais, como você e a gente, acarreta o uso do verbo na terceira pessoa, porém a pessoa do discurso refere-se, respectivamente, à segunda do singular e à primeira do plural. Duarte (1993) mostra que a segunda pessoa é o lugar por onde o sujeito explícito começa a ser inserido no quadro pronominal. A partir daí, esse uso se estende para a primeira pessoa, inicialmente a do plural, em virtude da inserção da forma nominal a gente, e, posteriormente, também na primeira pessoa do singular. Paredes Silva (1998) também ressalta que há condições funcionais, como a da distintividade ou a da iconicidade, que atuam sobre o uso de sujeitos explícitos. Citando Barrenechea (PAREDES SILVA, 1998, p. 125), Paredes Silva afirma que motivações comunicativas atuam sobre sujeitos explícitos de segunda pessoa, pois seu uso estaria vinculado ao interesse do locutor de manter o vínculo com o interlocutor e chamar sua atenção sobre a conversação. No caso da primeira pessoa do singular, objeto de estudo do presente artigo, apesar de haver usos em que não há 
ambiguidade morfológica, por vezes há necessidade de maior autoria sobre o que se fala, daí maior uso do sujeito pronominal explícito.

Paredes Silva (1988), em um estudo sociofuncionalista do sujeito pronominal em setenta cartas de cunho informal, manuscritas nas décadas de 1970 e 1980 por quarenta e dois missivistas, verifica que a não expressão do sujeito pronominal tem caído em desuso. Neste processo de mudança linguística, destacam-se três variáveis: (1) a faixa etária, já que os jovens favorecem mais o preenchimento de sujeito pronominal de primeira pessoa do que os mais velhos; (2) a ênfase, pois quando o missivista quer enfatizar algo utiliza mais sujeitos explícitos na primeira e segunda pessoas; e (3) a conexão discursiva, que se refere à "estreita a ligação do que se diz numa oração com o que se disse na precedente, também menor a necessidade de um sujeito expresso" (PAREDES SILVA, 1988, p. 298). Outra variável importante é a ambiguidade morfológica e contextual, que aponta para um favorecimento do preenchimento do sujeito pronominal em contextos ambíguos.

Duarte (1993), em um estudo sobre o sujeito pronominal sob o prisma da Sociolinguística Paramétrica, analisa o fenômeno linguístico em peças teatrais cariocas de cunho popular, escritas no período entre 1845 e 1992. A pesquisadora observa, a partir de 1918, modificação acentuada do uso do sujeito pronominal, já que, até esta data, havia "nítida preferência pelo sujeito nulo" (DUARTE, 1993, p. 111). Observando o quadro pronominal, a pesquisadora revela que os primeiros contextos que apresentam maior preenchimento são os voltados à segunda pessoa, dada a inserção do pronome você. Para a autora, a mudança do sujeito pronominal está diretamente vinculada aos novos paradigmas flexionais inseridos no português brasileiro: de um paradigma de seis flexões (denominado Paradigma 1), passa-se para um paradigma de quatro flexões (Paradigma 2, com a segunda e a terceira pessoas do singular sendo expressas por formas verbais de terceira pessoa) e, posteriormente, uso concomitante com o paradigma de 3 flexões (Paradigma 3, em que a primeira pessoa do plural também é expressa por forma de terceira pessoa do singular). No que diz respeito à primeira pessoa, a autora amalgama as do singular e plural e verifica a enorme diminuição no uso do sujeito nulo a partir de 1918, acentuando-se ainda mais na segunda metade do século XX. Por outro lado, Duarte também constatou que há contextos de resistência aos sujeitos pronominais explícitos, como os casos de orações independentes, com verbos simples, e de estruturas com correferência, tanto na subordinada, quanto na principal.

A partir dos resultados apontados, voltamos à descrição do corpus analisado. 


\section{As cartas pessoais: uma reconstrução histórica da variação linguística capixaba nos novecentos}

Com o intuito de observarmos a comunidade de fala capixaba do início do século XX, analisamos cartas pessoais desse período, uma vez que podem dar pistas sobre a variedade linguística da época. O corpus utilizado compõe-se de 33 cartas pessoais, sendo 28 da primeira década dos novecentos e 5 da segunda década. Conforme já mencionado, os estudos em sociolinguística, comumente, são voltados a observar a variação em corpora de fala, porém também há análises voltadas para textos escritos, especialmente no caso de ausência de material de fala.

Defendemos, neste artigo, o estudo linguístico da escrita em cartas pessoais como uma possibilidade de se observar a mudança linguística, uma vez que a carta pessoal é um texto de produção real comunicativa entre duas ou mais pessoas, apresentando algumas características comuns à fala, como aponta Marcuschi (2010, p. 41) na figura abaixo.

Figura 1 - Distribuição dos Gêneros textuais no contínuo fala/escrita

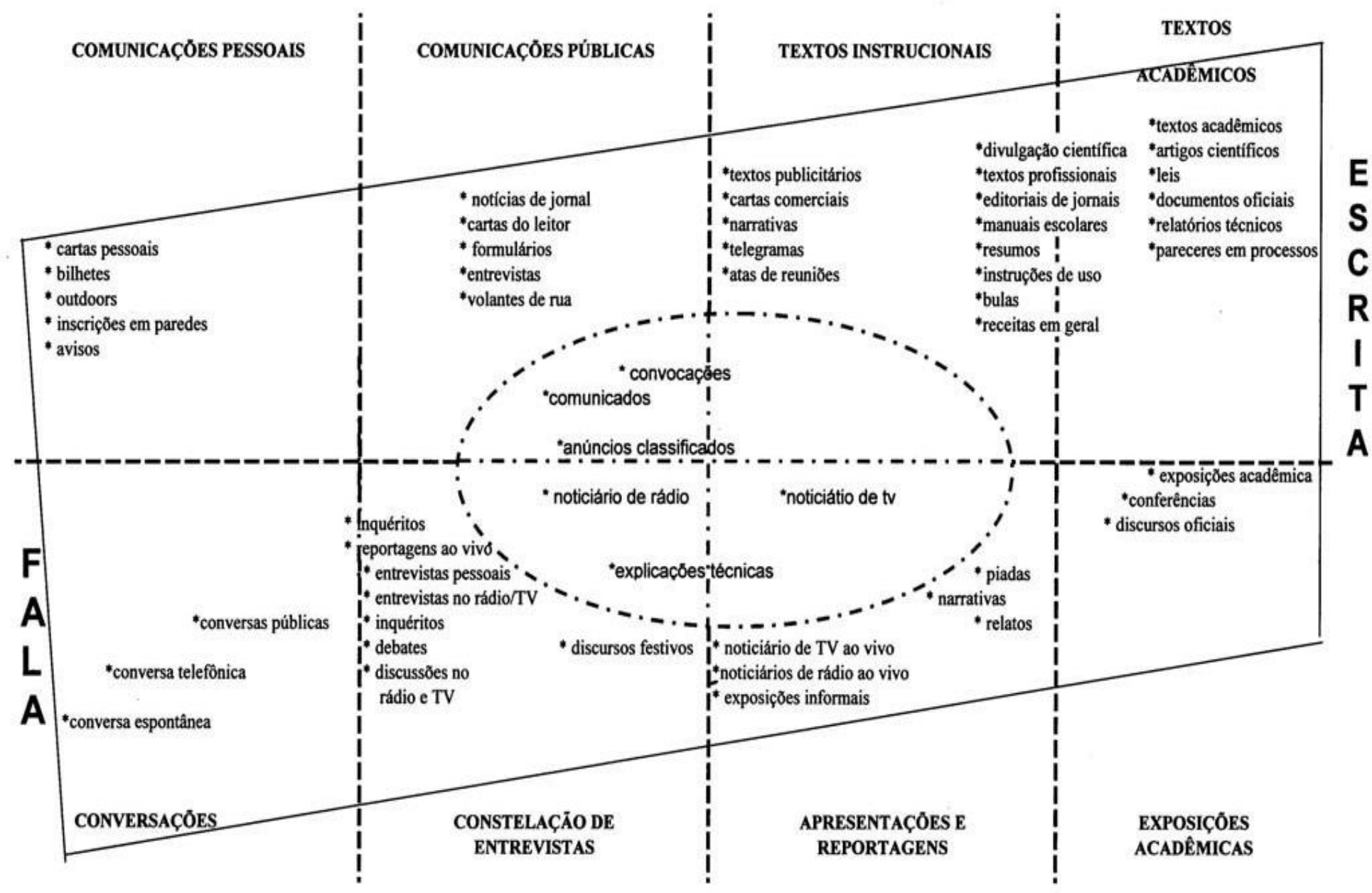

Fonte: Marcuschi (2010, p. 41). 
Ciapuscio et al. (2006, p. 3) propõem um enquadramento da produção escrita a partir da proximidade ou distanciamento da comunicação, conforme exposto na Figura 2 abaixo:

Figura 2 - Proximidade $x$ Distância Comunicativa

\begin{tabular}{|l|l|}
\hline (a) caráter privado da comunicação & (a') caráter público da comunicação \\
\hline $\begin{array}{l}\text { (b) intimidade ou familiaridade dos } \\
\text { interlocutores, maior conhecimento partilhado }\end{array}$ & $\begin{array}{l}\text { (b') ausência de intimidade ou de } \\
\text { familiaridade, menor conhecimento partilhado }\end{array}$ \\
\hline (c) forte participação emocional & (c') falta de participação emocional \\
\hline (d) inserção do discurso no contexto situacional & (d') não inserção do discurso no contexto \\
\hline (e) referencialização direta (ego-hic-nunc) & (e') referencialização indireta \\
\hline $\begin{array}{l}\text { (f) proximidade local e temporal entre os } \\
\text { interlocutores (comunicação face a face) }\end{array}$ & $\begin{array}{l}\text { (f') distância local e temporal entre os } \\
\text { Interlocutores }\end{array}$ \\
\hline (g) intensa cooperação & (g') fraca cooperação \\
\hline (h) dialogicidade & (h') monologicidade \\
\hline (h) dialogicidade & (i') reflexão \\
\hline (j) pluralidade temática & (j') fixação do tema \\
\hline
\end{tabular}

Fonte: Ciapuscio et al. (2006, p. 3).

Ao observarmos o quadro, notamos que as cartas pessoais ora analisadas se encontram, na maior parte das vezes, mais voltadas para os pontos do lado esquerdo, pois são comunicações de caráter privado, apresentam intimidade e familiaridade entre os interlocutores, há forte carga emocional, inserção do discurso no contexto interacional, dialogicidade e pluralidade temática. Em alguns poucos trechos das cartas, o missivista pode se mostrar mais distante para argumentar a favor de algum ponto de vista, voltando sua escrita mais às características do lado direito do quadro, mostrando mais distanciamento de seu interlocutor.

As cartas que compreendem o corpus de nossa pesquisa foram escritas por Oswald Guimarães, uma figura ilustre que fez parte da elite capixaba, tendo sido prefeito da capital do Espírito Santo e vice-presidente da Associação Comercial, havendo, inclusive, nos dias atuais, uma praça, em sua homenagem, em Bento Ferreira, bairro de classe média da cidade de VitóriaES. O missivista possuía escolaridade de ensino fundamental incompleto, tendo cursado até o terceiro ano ${ }^{7}$. Por meio das cartas, pudemos depreender que foi um indivíduo circunscrito em

\footnotetext{
${ }^{7}$ Até os anos 20, a educação brasileira comportou-se como um instrumento de mobilidade social. Os estratos que detinham o poder econômico e político utilizavam-na como distintivo de classe. As camadas médias procuravamna como a principal via de ascensão social, prestígio e integração com os estratos dominantes. Nesta sociedade, ainda não havia uma função "educadora" para os níveis médio e primário, razão pela qual eles não mereceram atenção do Estado, senão formalmente. A oferta de escola média, por exemplo, era incipiente, restringindo-se, praticamente, a algumas iniciativas do setor privado (ROMANELLI, 1983 apud MINISTÉRIO DA EDUCAÇÃO DE BRASIL [MEC]; INSTITUTO NACIONAL DE ESTUDOS E PESQUISAS EDUCACIONAIS ANÍSIO TEIXEIRA [INEP]; ORGANIZACIÓN DE ESTADOS IBERO AMERICANOS [OEI], 2003, p. 21).
} 
ambiente letrado, uma vez que frequentava teatro, recitais, cinema e os bailes da elite capixaba. As missivas manuscritas por ele são destinadas à noiva, Hylda, e referem-se, normalmente, a notícias da família, notícias sobre a vida do casal, seus planos amorosos e, também, a negócios da família.

\section{A hipótese funcionalista da variável ambiguidade: aliança entre gregos e troianos}

Inicialmente, podemos dizer que não há ambiguidade para a primeira pessoa do singular, uma vez que há uma marca verbal nítida, como a que ocorre nos tempos verbais do presente (canto), do pretérito perfeito (cantei), do futuro do presente (cantarei) do indicativo. Contudo, nos demais modos e tempos verbais, a ambiguidade na primeira pessoa é latente, podendo ser confundida com a segunda e terceira pessoa do singular, você e ele, respectivamente e, também, com a nova primeira do plural, a gente. É o que se observa, por exemplo, no pretérito imperfeito do indicativo, em que a marca morfológica de tempo-modo e número-pessoa, - $v a$, pode se referir à primeira pessoa do singular $(e u)$, à segunda (você), à terceira (ele, ela) e à primeira do plural (a gente).

Segundo Rocha Lima (2011, p. 395), nestes casos de ambiguidade gerada em decorrência da morfologia verbal, o sujeito deve ser preenchido:

\footnotetext{
“- Queres talvez que vá acordar Carlos, para que me faça o favor de aceitar minhas prendas?" (JÚLIO DINIS) Quando o sentido não distingue, evite-se a ambiguidade pela expressão do sujeito; tal se dá entre as formas da $1^{\mathrm{a}}$ e $3^{\mathrm{a}}$ pessoas do singular do imperfeito, e do mais-que-perfeito do indicativo; futuro do pretérito; presente, imperfeito e futuro do subjuntivo, e infinitivo pessoal: lia, lera, leria, leia, lesse, ler. (ROCHA LIMA, 2011, p. 395, grifos nossos)
}

Cunha e Cintra (2001) trazem uma abordagem semelhante à empregada por Rocha Lima, ao afirmarem que o sujeito pronominal é usado “a) quando se deseja, enfaticamente, chamar a atenção para a pessoa do sujeito: [...] b) para opor duas pessoas diferentes [...] c) quando a forma verbal é comum à primeira e à terceira pessoa do singular e, por isso, se torna necessário evitar o equívoco" (CUNHA; CINTRA, 2001, p. 282-283).

Quanto à variável ambiguidade, notamos um consenso entre o que prescreve a tradição gramatical e a hipótese funcionalista, segundo a qual, a partir da condição de distintividade, há "uma tendência para a informação semanticamente relevante ser mantida na estrutura superficial” (KIPARSKY, 1972 apud POPLACK, 1980, p. 372). Portanto, uma estrutura linguística, indispensável para a comunicação ocorrer de maneira eficaz, tende a não ser apagada. No caso dos sujeitos pronominais, quando há margem de dúvida sobre quem seja o sujeito, ocorre a tendência de ele não ser apagado. Em outras palavras, no caso de nossas cartas, 
o missivista tende a não deixar margem de dúvida à destinatária sobre quem é o sujeito da ação, evitando, assim, expressões/formas ambíguas.

Paredes Silva (1988) observa que a análise da ambiguidade pautada, apenas, na marca morfológica do verbo não é suficiente para o entendimento do fenômeno, uma vez que também há casos em que a ambiguidade pode estar presente no contexto discursivo. Para resolver a questão, a pesquisadora propõe três possibilidades para o entendimento da ambiguidade dos sujeitos pronominais: verbos morfologicamente não ambíguos; verbos morfologicamente ambíguos, como os casos previstos na tradição gramatical (pretérito imperfeito, futuro do pretérito do indicativo e tempos do subjuntivo), contudo, sem ambiguidade contextual; verbos morfologicamente ambíguos, com ambiguidade textual. A proposta de Paredes Silva é explicitada abaixo com exemplos retirados de nosso corpus:

- Verbos morfologicamente não ambíguos: “Ø Irei assistir e $\varnothing$ te contarei” (16 de março de 1919): a marca morfológica do verbo é suficiente para a identificação do sujeito

- Verbos morfologicamente ambíguos e contexto não ambíguo: "Como Ø já te disse pela manhã, a recepção aqui foi excellente. Hoje temos folga." (carta de Oswald, datada de 2 de novembro 1916). Por haver uma interlocução anterior, por meio das missivas, entre emissor e destinatária, fica implícito qual seria o sujeito do verbo dizer.

- Verbos morfologicamente ambíguos e contexto ambíguo: "E depois já sabe: puxão de orelhas quando eu chegar ahi." (carta de Oswald, datada de 5 de maio de 1917). Neste caso específico, se o sujeito não estivesse expresso, perguntaríamos quem levaria o puxão de orelhas.

Destacada a variável analisada, passaremos, a seguir, a analisar os resultados obtidos.

\section{Descrição dos resultados}

Para descobrirmos se a ambiguidade ${ }^{8}$, de fato, favorece maior preenchimento de sujeito pronominal, foi necessário que fizéssemos um teste estatístico para análise. Para tal, utilizamos o programa Goldvarb X (SANKOFF; TAGLIAMONTE; SMITH, 2005), que fez os cálculos matemáticos e estatísticos a partir dos quais obtivemos os resultados sobre contextos que favorecem e os que desfavorecem o uso do sujeito pronominal explícito. Guy e Zilles (2007, p. 211) ponderam que a análise norteada por peso relativo é um tipo de análise multivariada, ao passo que a voltada a percentuais é um cálculo univariado. Nas palavras dos autores:

\footnotetext{
${ }^{8}$ Vale ressaltar que a presente análise é um recorte da dissertação de Massariol (2018a), na qual a pesquisadora analisou mais variáveis linguísticas e, também, extralinguísticas. A variável ambiguidade foi a segunda selecionada pelo programa, ficando atrás, somente, da variável ênfase.
} 
Os pesos calculam os efeitos dos fatores de cada grupo em relação ao nível geral de ocorrência das variantes e resultam de uma análise multivariada. O efeito, assim calculado, pode ser neutro $(0,50)$, favorecedor (acima de 0,50$)$ ou desfavorecedor (abaixo de 0,50 ) em relação à aplicação da regra em estudo. (GUY; ZILLES, 2007, p. 211)

Tendo isso em vista, obtivemos o seguinte resultado, comparado ao obtido por Paredes Silva (1988):

Tabela 1 - Efeito da ambiguidade sobre a expressão do sujeito pronominal de primeira pessoa do singular: comparativo

\begin{tabular}{|l|l|r|r|}
\hline Ambiguidade & Frequência & Peso Relativo & $\begin{array}{r}\text { Paredes Silva } \\
(\mathbf{1 9 8 8 ,} \text {. 163) }\end{array}$ \\
\hline $\begin{array}{l}\text { Verbo morfologicamente não } \\
\text { ambíguo }\end{array}$ & $11,9 \%(63 / 530)$ & 0,465 & $\begin{array}{r}19 \% \\
(283 / 1469)\end{array}$ \\
\hline $\begin{array}{l}\text { Verbo morfologicamente } \\
\text { ambíguo e contexto não ambíguo }\end{array}$ & $15,7 \%(8 / 51)$ & 0,596 & $43 \%(61 / 142)$ \\
\hline $\begin{array}{l}\text { Verbo morfologicamente } \\
\text { ambíguo e contexto ambíguo }\end{array}$ & $73,7 \%(14 / 19)$ & $\underline{0,948}$ & $90 \%(35 / 39)$ \\
\hline Total & $14,2 \%(85 / 600)$ & $\begin{array}{r}\text { Range: } 483 \\
\text { Input: } 0,103\end{array}$ & $\begin{array}{r}22,96 \% \\
(379 / 1650)\end{array}$ \\
\hline
\end{tabular}

Fonte: Massariol (2018a, p.103) adaptado.

É importante destacar que as formas variantes (presença $x$ ausência de sujeito pronominal) se alternam, isto é, a variante nula aparece, também, em circunstâncias de ambiguidade, assim como a explícita ocorre em situações não ambíguas. Cumpre notar, no entanto, que esses casos aparecem com menor incidência

As duas amostras analisadas são constituídas por textos pertencentes ao mesmo gênero textual - cartas pessoais -, porém são de épocas distintas: as de Paredes Silva compreendem as décadas de 1970 e 1980, enquanto as aqui analisadas são das décadas de 1910 e 1920. Seus resultados são bastante similares: verbos morfologicamente não ambíguos, isto é, aqueles que possuem marca flexional que identifica o sujeito, são os que desfavorecem o sujeito pronominal explícito. Em ambas as amostras, a ambiguidade favorece o sujeito pronominal explícito. Os resultados das cartas pessoais escritas por um capixaba nos anos 1919 e 1920 também são similares aos encontrados por Duarte (1993), que apontam um aumento no uso de sujeitos pronominais explícitos de primeira pessoa nas peças teatrais escritas a partir de 1918. É preciso ressalvar que os dados aqui analisados são apenas da primeira pessoa do singular, ao passo que os de Duarte se referem a singular e plural.

Duarte (1993) afirma que a mudança na expressão do sujeito pronominal decorre da inserção de você e a gente no quadro pronominal, o que encadeia um novo paradigma flexional, 
que passa a ter três ou quatro formas flexionadas, diferentemente do anterior que apresentava seis formas. Com um número menor de flexões de pessoa, há, consequentemente, a necessidade de sujeitos pronominais explícitos, sobretudo, nas pessoas do discurso que fazem sua concordância na terceira pessoa para que se distingam as pessoas gramaticais, apesar de possuir, em muitos tempos verbais, uma flexão distinta da que ocorre com a segunda e com a terceira pessoas, também, uma tendência de aumento de sujeitos pronominais explícitos de primeira pessoa do singular. É o que notamos ao compararmos nossos resultados com os de Paredes Silva (1988): nas cartas capixabas das décadas de 1910 a 1920, há 14,2\% de sujeitos pronominais explícitos, passando, nas cartas cariocas das décadas de 1970 a 1980, a 22,96\%. Portanto, com o passar do tempo, há cada vez maior ocorrência de sujeitos pronominais de primeira pessoa do singular explícitos.

A necessidade de sujeitos pronominais explícitos pode, portanto, como defendido por Duarte (1993), ter ocorrido em função de um rearranjo no paradigma flexional. Entretanto, essa não é a única razão, conforme exposto por Paredes Silva (1998). Há, também, razões de ordem funcional, entre elas a condição de distintividade ou o princípio da iconicidade. Pode-se ter por hipótese que a inserção de você e a gente são o início do processo, porém não são fatores exclusivos. A necessidade de deixar clara a comunicação faz com que se usem mais sujeitos pronominais explícitos em contextos morfologicamente ambíguos e essa necessidade de se deixar claro o sujeito faz com que seja usado também em contextos não ambíguos, como na maioria dos casos de primeira pessoa do singular.

Entre os fatores analisados por Massariol (2018a), além da ambiguidade morfológica e contextual, destacam-se a ênfase ao sujeito, a mudança do referente, o menor envolvimento do escrevente com o tema e a natureza do tema. É o que observamos na tabela abaixo:

Tabela 2 - Variáveis estatisticamente significativas sobre o sujeito pronominal explícito de primeira pessoa do singular

\begin{tabular}{|l|l|r|}
\hline Variáveis & Frequência & Peso Relativo \\
\hline \multicolumn{2}{|c|}{ Enfase ao sujeito } \\
\hline Sujeito não enfático & $9,6 \%(47 / 492)$ & 0,440 \\
\hline Sujeito enfático & $35,2 \%(38 / 108)$ & 0,816 \\
\hline \multicolumn{1}{|c|}{ Mudança de referente } & 0,423 \\
\hline Referente igual ao anterior & $10,2 \%(40 / 393)$ & 0,643 \\
\hline Referente diferente do anterior & $21,7 \%(45 / 207)$ & 0,456 \\
\hline \multicolumn{2}{|c|}{ Envolvimento do escrevente com o tema } \\
\hline
\end{tabular}




\begin{tabular}{|l|l|r|}
\hline Maior envolvimento com o tema & $21,7 \%(38 / 175)$ & 0,605 \\
\hline \multicolumn{2}{|c|}{ Natureza do tema } \\
\hline Tema objetivo & $8 \%(38 / 477)$ & 0,468 \\
\hline Tema subjetivo & $18,4 \%(7 / 38)$ & 0,832 \\
\hline Total & $14,2 \%(85 / 600)$ & \\
\hline
\end{tabular}

Fonte: Massariol (2018a) adaptado.

Com esses resultados, podemos, então, afirmar que o pronome sujeito é tido como informação semanticamente relevante, sendo sua expressão, nos casos de ambiguidade morfológica, devido à condição de distintividade. Nos demais casos, a necessidade de deixar mais clara a comunicação faz com que seja usado mesmo em casos sem ambiguidade morfológica. É o que vemos nas pesquisas aqui apresentadas e, também, na de Genuíno (2017), que, ao analisar a expressão do sujeito pronominal na fala capixaba, apresenta a importância da variável ambiguidade. Em seus resultados, Genuíno mostra que verbos morfologicamente ambíguos, isto é, aqueles em que há mais de um candidato a sujeito, são os que mais favorecem sujeitos pronominais explícitos de primeira pessoa (GENUÍNO, 2017, p. 102). Em comunicação pessoal, Genuíno mostrou que, no caso da primeira pessoa do singular, a ambiguidade também foi uma variável que favoreceu a expressão do sujeito pronominal explícito: dos 5335 dados, 70\% são de sujeitos explícitos e 77,4\% são de casos em que há ambiguidade morfológica. Notamos, assim, que, mesmo na fala, com mais de $70 \%$ de sujeitos pronominais explícitos, a ambiguidade é uma variável que condiciona esse uso, apesar de não ser a única e, conforme expresso por Paredes Silva (1998), ter outras questões funcionais atuantes sobre esse uso.

\section{Considerações Finais}

O artigo em tela teve como objetivo contribuir para o enriquecimento de pesquisas que têm como foco um alinhamento de duas correntes teóricas: a Sociolinguística e o Funcionalismo. No modelo teórico adotado, pudemos verificar que o fenômeno variável da expressão do sujeito pronominal sofre influência de um fator morfológico-discursivo, a ambiguidade do verbo, que tem relação com um aspecto funcional da língua: a condição da distintividade. Notamos que há um maior favorecimento de sujeitos expressos quando há verbos morfologicamente ambíguos, especialmente quando o contexto discursivo também é ambíguo. Nestes casos, o uso do sujeito pronominal expresso supre a necessidade de clareza 
comunicativa, fato este já descrito pela tradição gramatical ao tratar do assunto. Podemos observar que a condição da distintividade, proposta por Kiparsky (1972 apud POPLACK, 1980) atua de modo relevante sobre o funcionamento de situações discursivas mais claras.

Cumpre destacar que a ambiguidade, conforme exposto ao longo do artigo, não é o único fator a atuar sobre o uso de sujeitos pronominais explícitos. Pesquisas como as de Paredes Silva (1988, 1998), Genuíno (2017), Massariol (2018a, 2018b) também mostram a atuação de outras variáveis, entre elas a ênfase e a conexão discursiva. Yacovenco e Massariol (2017), ao analisarem dados de fala de mulheres universitárias em diversas situações comunicativas, observa que, ao lado dos fatores mencionados, há, também, questões relativas a estilo, uma vez que há mudanças devidas as audiências.

A presente pesquisa ratifica, portanto, resultados de outros estudos (PAREDES SILVA, 1988; DUARTE, 1993; GENUÍNO, 2017), os quais demonstram que no português brasileiro a expressão do sujeito pronominal está a cada dia mais presente. Notamos, na presente pesquisa, que este resultado já se apresentava em cartas pessoais do início do século XX, mesmo que em um percentual pequeno. Nossos dados corroboram o fato de que cartas pessoais são um importante material a ser analisado em pesquisas sociolinguísticas na ausência de dados de fala, uma vez que permitem que se lancem hipóteses sobre a língua usada na época estudada. Cumpre ressaltar que a escrita tende a ser mais conservadora que a fala, conforme demonstrado em diversos estudos, entre eles o de Duarte (1993); e sujeitos pronominais explícitos ocorrem preferencialmente em contextos em que há ambiguidade morfológica e contextual, em situações enfáticas e com menor conexão discursiva e maior distanciamento entre os interlocutores, sinalizado por Paredes Silva (1998) e Massariol (2018a, 2018b).

\section{Referências}

CIAPUSCIO, G.; JUNGBLUTH, K; KAISER, D; LOPES, C. In: (Eds.). Sincronía y diacronía de tradiciones discursivas em Latinoamérica. Madrid: Iberoamericana, 2006.

CONDE SILVESTRE, J. C. Sociolingüística histórica. Madrid: Gredos, 2007.

CUNHA, C.; CINTRA, L. Nova gramática do português contemporâneo. 6 . ed. Rio de Janeiro: Lexikon, 2013.

DUARTE, M. E. L. Do pronome nulo ao pronome pleno: a trajetória do sujeito no português brasileiro. In: ROBERTS, I.; KATO, M. A. (Org.). Português brasileiro: uma viagem diacrônica. Campinas: Ed. Unicamp, 1993. p. 107-128. 
FISHER, J. L. Influências sociais na escolha de variantes linguísticas. Trad. Elba I. Souto. In: FONSECA, M. S.; NEVES, M. F. (Org.). Sociolingüística. Rio de Janeiro: Eldorado, 1974 [1958].

GENUINO, W. R. A. A expressão do sujeito pronominal no português falado em Vitória/ES. 2017. 130 f. Dissertação (Mestrado em Estudos Linguísticos) - Programa de PósGraduação em Linguística, Universidade Federal do Espírito Santo, Espírito Santo, 2017.

GIVÓN, T. Functionalism and Grammar. Amsterdam: John Benjamins, 1995.

GÖRSKI, E. M.; TAVARES, M. A. Reflexões teórico-metodológicas a respeito de uma interface sociofuncionalista. Revista do GELNE, Natal, v. 15. p. 79-101, 2013.

GUY, G.; ZILLES, A. M. Sociolinguística quantitativa - instrumental de análise. São Paulo, Parábola, 2007.

HERNÀNDEZ-CAMPOY, J. M.; SCHILLING, N. The Application of the Quantitative Paradigm to Historical Sociolinguistics: Problems with the Generalizability Principle. In: HERNÀNDEX-CAMPOY; CONDE SILVESTRE. The Handbook of Historical Sociolinguistics. Oxford: Wiley-Blackwell, 2012. p. 63-79.

LABOV, W. Principles of Linguistic Change: Internal factors. Oxford/Cambridge: Blackwell Publishers, 1994.

LABOV, W. Padrões sociolinguísticos. São Paulo, Parábola, 2008 [1972].

LIMA-HERNANDES, M. C. P. A interface sociolinguística/gramaticalização: estratificação de usos de tipo, feito, igual e como. Tese (Doutorado em Linguística) Universidade Estadual de Campinas, Campinas, 2005.

MASSARIOL, C. B. A expressão do sujeito pronominal em cartas e postais capixabas do Século XX. 2018. 135 f. Dissertação (Mestrado em Estudos Linguísticos) - Programa de PósGraduação em Linguística, Universidade Federal do Espírito Santo, Espírito Santo, 2018a.

MASSARIOL, C. B. A expressão do sujeito pronominal na fala de mulheres universitárias capixabas: uma análise comparativa. In: CONGRESSO NACIONAL DE ESTUDOS LINGUÍSTICOS, 4, 2017, Vitória. Caderno de resumos. Vitória: PPGEL/Ufes, 2018b. p. 280.

MARCUSCHI, L. A. Produção textual, análise de gêneros e compreensão. São Paulo: Parábola Editorial, 2009.

MARCUSCHI, L. A. Da fala para a escrita: atividades de retextualização. 10. ed. São Paulo: Cortez, 2010.

NEVES, M. H. M. Estudos funcionalistas no Brasil. D.E.L.T.A., v. 15, n. esp., p. 71-104. 1999.

PAREDES SILVA, V. L. Cartas cariocas: a variação do sujeito na escrita informal. 1988. Tese (Doutorado) - Universidade Federal do Rio de Janeiro, Rio de Janeiro, 1988. 
PAREDES SILVA, V. L. Variação e funcionalidade no uso de pronomes de $2^{\mathrm{a}}$ pessoa do singular no português carioca. Revista de Estudos Linguísticos, Belo Horizonte, v. 7, n. 2, p. 121-138, 1998.

PINHEIRO, F. P. Variação e gramaticalização: um estudo sobre a redução fonética do item estar. Revista de Estudos Linguísticos, Belo Horizonte, v. 28, n. 3, p. 1131-1159, 2020.

POPLACK, S. Deletion and Disambiguation in Puerto Rican Spanish. Language, v. 56, n. 2, p. $371-85,1980$.

ROCHA LIMA, C. H. Gramática Normativa da Língua Portuguesa. 49. ed. São Paulo: José Olympio, 2012.

ROMANELLI, O. O. História da educação do Brasil (1930/1973). Petrópolis: Vozes, 1986.

SANKOFF, D.; TAGLIAMONTE S. A.; SMITH E. GoldVarb X - A multivariate analysis application. Toronto: Department of Linguistics; Ottawa: Department of Mathematics, 2005. Disponível em: http://individual.utoronto.ca/tagliamonte/goldvarb.html. Acesso em: 28 mai. 2019.

TAVARES, M. A. Um estudo variacionista de AÍ, DAÍ, ENTÃO e E como conectores sequenciadores retroativo-propulsores na fala de Florianópolis. 1999. Dissertação (Mestrado em Linguística) - Universidade Federal de Santa Catarina, Florianópolis, 1999.

TESCH, L. M. A expressão do tempo futuro no uso capixaba: variação e gramaticalização. 2011. 192 f. Tese (Doutorado em Linguística) - Pós-Graduação em Linguística, Faculdade de Letras, Universidade Federal do Rio de Janeiro, Rio de Janeiro, 2011.

WEINREICH, U.; LABOV, W.; HERZOG, M. Fundamentos empíricos para uma teoria da mudança linguística. Trad. Marcos Bagno. São Paulo: Parábola, 2006 [1968].

YACOVENCO, L. C.; MASSARIOL, C. B. A expressão do sujeito pronominal na fala de uma universitária: uma análise baseada no estilo. Revista (Con)Textos Linguísticos, Vitória, v. 11, p. 104-123, 2017.

\section{Sobre as autoras}

Caroliny Batista Massariol (Orcid iD: http://orcid.org/0000-0002-8638-0934)

Doutoranda (bolsista da CAPES) no Programa de Pós-Graduação em Linguística da Universidade Federal do Rio de Janeiro (UFRJ); mestra em Estudos Linguísticos pela Universidade Federal do Espírito Santo (UFES); licenciada em Letras - Português pela mesma instituição.

Lilian Coutinho Yacovenco (Orcid iD: http://orcid.org/0000-0003-3568-0539)

Doutora e mestra em Letras (Letras Vernáculas) pela Universidade Federal do Rio de Janeiro (UFRJ); graduada em Letras - Português e Literaturas de Língua Portuguesa pela mesma instituição. É professora do Departamento de Línguas e Letras e do Programa de Pós-Graduação em Linguística da Universidade Federal do Espírito Santo (UFES). 